\title{
Reflections on MOOC Craze in China
}

\author{
Li Hao ${ }^{1}$, Xing-hua Sun ${ }^{2}$ \\ 1) Department of Political Science and Law, Hebei North University, Zhangjiakou, Hebei ,China \\ 2)School of Information Science and Engineering, Hebei North University, Zhangjiakou, Hebei, China
}

\begin{abstract}
MOOC is getting increasingly popular in the field of education. Many key universities have adopted MOOC and the local universities are ready to have a try. The advantages and disadvantages of the pervasive MOOC craze, however, should be objectively considered. The definition, characteristics, types of MOOC are analyzed in this paper and its development in China is presented. As a technical approach, MOOC, with all its advantages, cannot bring out the real innovation for higher education..
\end{abstract}

Keywords-MOOCs, online course, online education, Chinese higher education

\section{对中国“慕课热” 的反思 \\ 郝丽 $^{1}$ 孙兴华 ${ }^{2}$ \\ ${ }^{1)}$ 河北北方学院法政学院, 张家口, 河北, 中国 \\ 2)河北北方学院信息科学与工程学院, 张家口, 河北, 中国}

摘 要 “慕课热” 是近两年教育领域新出现的现象。国内重点大学纷纷加盟慕课, 普通高校也对慕课跃跃欲试。面对不断升温的 慕课风潮, 需要冷静、客观地看待慕课的优劣。通过分析慕课的定义、特点、类型以及它在中国的发展现状, 笔者认为慕课既有其独 特的优势，有助于推进中国的高等教育改革，也有其局限性，作为一种技术性的工具，它无法带来高等教育真正的变革。

关键词＼cjkstart慕课，在线课程，在线教育，中国高等教育

\section{1. 引言}

随着互联网技术的迅速发展与普及, 几乎所有的行业 都受到其或大或小, 或浅显或深远的影响, 教育行业也不 例外。当下流行的 “慕课” (MOOC) 就是传统教育受互联 网技术影响的显著案例。

\section{2. 慕课及其特点、类型}

慕课 $(\mathrm{MOOC})$ 是一个外来词汇, 其全称是 Massive Open Online Courses, 意为 “大规模、开放性、在线课程”。慕课 最早是由美国的布莱恩・亚历山大 (Bryan Alexander) 和戴 夫 - 科米尔 (Dave Cormier) 提出的, 后来用在西门思和斯 蒂芬・唐尼斯于 2008 年合作开设的一门大型网络课程中。

\section{1 慕课的定义}

关于慕课的定义, 教育界目前还没有形成一个统一的 看法。笔者认为以下定义比较合理: 慕课是指提供自由选
择, 开放注册并具有开放式结构的在线开放课程, 它将社 交网络与可获取的网络资源进行整合, 由所在研究领域的 专家来开设并推进。

\section{2 慕课的特点}

从字面分析, 我们会发现 MOOCS 有三个特点: Massive、Open、Online。

(1) Massive 即为大规模。一门 MOOC 课程注册学习的学 生人数众多, 动轧上万人, 乃至十几万人。仅能容纳 几十、几百人的传统课程完全无法与之相提并论。据 统计, 注册学生最多的一门课, 同时有 190 多个国家 的 16 万人在学。因为上课的人多, 一个学生提出问题, 15 分钟内肯定有人回答, 这种几乎没有时差的回应对 学生是一种动机上的激励。由于人数众多, 在慕课平 台上, 即便发帖的人比例不大, 也足以覆盖各种观点, 不仅促进同伴之间的互助合作, 更有助于教学目标的

河北省高等教育教学改革研究与实践基金项目支持（资助号：2015GJJG138） 
完成。

(2) Open 即为开放性。慕课坚持开放的理念, 实行课程注 册开放、学习内容开放、学习时间开放、学习方法开 放、教学方法开放、学习评价开放, 所有的慕课平台 都没有任何准入限制。慕课以兴趣为导向, 提倡 “有 教无类”, 只要是想学习的人, 不分性别、种族、地域, 都可以注册参与。这种开放性打破了大学的围墙, 使 真正想学习的人轻易获得优质教学资源, 促进了教育 公平。据美国斯坦福大学调查研究发现, 参与慕课学 习的大多数是已经毕业、工作的人。他们来慕课注册 学习的目的或者是为了更新知识, 或者是为了实现自 己当年想学而没有学的愿望。教这些真正想学习的人, 会使教师感到愉快, 全身心的投入到授课中, 从而最 大程度上提升授课效果。由于有些学生是有相关工作 经验的, 他们完全可以代替助教回答别的学生提出的 问题, 从而降低教师和助教的工作量, 提升教师的工 作效率。

(3) Online 即为在线。慕课是在线学习, 无论教师还是学 生, 都不必亲临现场。不管学员身处何时何地, 只要 通过互联网, 轻点鼠标, 就可以参与学习。由于不受 时空限制, 职场人士可以随时利用自己的碎片时间进 行学习, 这使终身学习成为可能。

\section{3 慕课的类型}

根据不同的教学模式, 慕课可以分为三种类型。 $\mathrm{xMOOC}$ 是网络远程教学课程, 以行为主义为其理论基础, 学生通过观看网络教学视频, 以在线学习、网上测评等方 式完成学习。cMOOC 为专题研讨, 以建构主义理论为指导, 以社交软件为平台, 在固定时间内探讨某个或某几个专题, 参与探讨的学生共同分享心得体会, 以完成知识构建。 tMOOC 是一种完成任务式的学习方式, 学生通过各种软件 工具编写作品, 并在网上提交。其中, xMOOC 是一种占主 导地位的开放课程授课模式。

慕课教育机构主要为美国大学财团或大学附属机构, 主要包括 Coursera,Edx,Udacity,

Khanacadem 和 Codeacademy 等。其中, Coursera,Edx,Udacity 被称为慕课教育的 “三驾马车”。这些 网络教学平台借助高校的优质教学资源打造各种高等教育 课程, 开创了 “指尖上的学习” 新模式, 为各类学生提供 了更多系统学习的机会。通过这些学习平台, 学生不仅可 以随意获取自己感兴趣的学习资源, 还可以通过设计个性 化的学习目标来帮助自己完成学习。

\section{3. 慕课在我国的发展现状}

大规模课程资源的公开性, 以名校名师为保证的课程 资源的优质性, 学习方式的个性化和自主选择性, 网络技 术提供的学习工具和学习资源的多元性等优势, 令 “慕课 热” 迅速蔓延全球。据不完全统计, 目前全球已开设 13000 多门慕课, 包括近 20 种语言。

如果 2012 年被称为世界 “慕课” 元年, 那么 2013 年 就是中国的 “慕课” 元年。从这一年开始, 我国的大学也 积极投身到慕课浪潮中。 2013 年 5 月 21 日, edx 宣布新 增 15 所高校的在线课程项目, 其中就包括北京大学和清华 大学。同年 7 月 9 日, 复旦大学、上海交通大学与 Coursera 签约。在不到 2 个月的时间内, 中国的著名大学 与慕课平台互动频频, 这恰恰表明慕课这种全新的教育模 式给中国的高等教育所带来的巨大冲击。此后, 陆续又有 著名高校加入慕课

可贵的是, 中国高校也在积极打造本土研发设计的慕 课平台。清华大学开发了 “学堂在线”, 上海交通大学开发 了 “好大学在线”, 高等教育出版社建设了精品资源共享课 平台, 上海交通大学与北京大学、清华大学、复旦大学、 浙江大学、南京大学、中国科学技术大学、哈尔滨工业大 学、西安交通大学等 $\mathrm{C} 9$ 中国常青藤大学及同济大学、大连 理工大学、重庆大学共建中国 “慕课” 平台等等。2013 年 8 月和 9 月, 华东师范大学慕课中心牵头, 成立了基础教育 的 C20 慕课联盟 (高中/初中/小学), 全国 20 余所重点高中、 20 余所知名初中和 20 余所知名小学加入该联盟。在 C20 慕课联盟（高中/初中/小学）成立一周年之际, “华师慕课” 网正式开通, 网站所有课程将对全国中小学生免费开放。 上海交通大学校长、中科院院士张杰评价 “慕课是印刷术 发明以来最大的教育革新, 更重要的是, 它将改革大学教 育, 重塑高等教育版图。”

同时, 国内越来越多的企业看到慕课远大的发展前景, 亦积极回应互联网技术对教育行业的推动。网易公开课、 过来人公开课、新浪、果壳网等相继推出自己的开放式网 络课程。优酷网与 Udacity 达成独家官方合作, 成为全国唯 一的 Udacity 课程发布渠道平台。目前, 优酷教育频道己经 上线数十门类别、近千集的翻译成中文的 Udacity 最新在线 视频课程。

一时之间, “慕课” 在我国蔚然成风, 成为教育界的热 词, “翻转课堂” “线上线下” 这样的词汇遍布各种教育论 坛、期刊杂志。在高校教育体制改革的大背景下, 加盟 “慕 课” 似乎已然成为解决高等教育各种弊病的良药, 成为一 种势在必行的趋势。几乎所有的高校都在关注 “慕课”, 都 期盼着投身于这个时髦的浪潮之中 


\section{4. 对 “慕课热” 的反思}

面对这股席卷全球的热潮, 我们有必要冷静下来对 “慕 课” 进行辩证的思考。慕课的产生自有其积极意义, 但是 如果把它当做包治百病的良药, 过分夸大其作用, 亦为不 妥。我们需要全面、客观的认识慕课, 既要看到其优点, 又要看到其局限性。既不能对 “慕课” 这种全新的教育模 式视而不见, 又不能过分夸大其作用, 全盘照搬、全民皆 “慕课”。

\section{1 “慕课” 的优点}

（1）慕课作为一种开放式的在线教育模式, 使优质教育资源 在更大范围内被共享。慕课的开放性, 在一定程度上打 破了大学的围墙, 它不仅可以推动高校之间的优质教育 资源的互换和共享, 还可以使这些优质资源惠及更多不 在校的学生。例如, 那些已经毕业参加工作的人可以通 过慕课平台注册学习, 以更新自己的知识体系; 那些当 年因为种种原因未能学习某门自己感兴趣的课程的人, 可以通过慕课获得学习该门课程的机会; 甚至那些不曾 上过大学的人, 也可以通过这种方式圆自己的大学梦。

(2) 慕课注重线上线下的互动合作, 这将在一定程度上刺激 传统教育的改革。缺乏互动是传统教育的弊病之一。在 传统课堂上, 教师作为主体, 完全主导教学过程, 即使 教师采用多媒体技术播放教学视频, 学生也只是作为被 动的客体接受这种单向的信息传播, 缺乏反馈与互动。 而慕课中的翻转课堂、微课等形式, 借助线上线下技术 会弥补这一缺陷。在线上课堂外, 学生先通过视频学习 标准化课程, 掌握基础知识; 在线下课堂内, 组织引导 学生进行相关内容的分享、探讨和问题解决, 变传统教 育的填鸭式、授课式、划一式为现代教育的参与式、咨 询式、多样式, 这样既实现了师生之间的有效互动, 又 有助于促进教学方式的革新、教学质量的提高。

(3) 慕课作为一种免费的在线教育模式, 为更多真正想学习 的人提供教育机会。慕课所有的课程都可以免费注册学 习, 只有当你想要获得相应的学分或学历证书时才需交 费。无论贫富、贵贱, 任何想要学习的人, 只要通过一 台联网的计算机就可以享受到全国乃至全世界最优质 的教育资源, 这对促进教育公平意义深远

(4) 慕课平台发布的微课程, 注重学生的学习体验, 有助于 提高学生的学习兴趣。据研究, 人在网上的注意力不超 过 15 分钟。慕课的课程被分割成 5-15 分钟的微课 程, 符合人的注意力特征。课程里设计有很多必须要回 答的小问题, 学习过程就像环环相扣的游戏闯关, 只有 回答正确才能继续听课。这样的进阶式学习不仅可以使 学生自主掌握学习进度, 还紧紧抓住了学生的注意力。
同时, 在学习过程中一旦遇到困难, 可以直接在平台上 提出来, 5 分钟内就会有教师或者其他学生提供相关参 考答案, 以助其成功闯关。游戏式学习体验会极大提高 学生的学习兴趣、学习质量。

(5) 模板化的慕课平台系统有助于教师进行教学精细化的 反思, 从而提高教学质量。在吸取多年网络教育经验的 基础上, 慕课形成了支持在线教育教学模式的平台系 统, 系统将其教学模式定型, 教师在做课过程中按照模 板做, 会促使教师进行教学精细化的反思, 以助课程质 量的提高。

总之, 慕课的积极意义在于: 大规模优质教育资源的 共享, 促进教育公平; 教学模式、教学手段的革新, 促进 高校教学改革, 进而促进创新人才的培养, 促进高等教育 质量的大幅提升。

\section{2 慕课的局限}

(1) 慕课是在线课程而不是在线教育。慕课只是一种在线课 程, 而不是严格意义上的在线教育。一般而言, 在线教 育有很高的完成率和优秀的教学质量保障, 提供学历教 育的机构大多还延续着面授与网上学习相结合的方式, 不仅要教学生知识, 还通过各种方式教他们做人做事的 道理, 扩大了教育范围, 提高了教育效果。而目前的慕 课仅有知识的传授, 不能算是严格意义上的教育, 只能 称为 “在线课程”, 是在线教育的一种形式而已

(2) 慕课先进的教育技术不等同于先进的教育。教育进步常 常要依靠诸如教育先进思想的传播、教育体制机制的创 新、教育内涵价值的提升、教育技术的进步等一系列因 素的合力推动。教育技术作为其中一种因素, 只能在一 定程度上改变教育形态。历史证明, 无论是收音机、电 视还是计算机等技术对教育的推进作用远未达到人们 所期望的的水平。慕课, 更多显现的是其先进的教育技 术, 如果不能与其他因素相结合, 它也不可能推动教育 现实的彻底改变。因此, 在当前阶段, 我们不应该对慕 课本身期望过高

(3) 慕课优秀的课程质量不等于同样优秀的培养质量。慕课 汇集全国乃至全世界名校名师主讲的优秀课程, 其课程 质量不可谓不高, 但是它在培养质量方面引发了诸多非 议。并不是所有的课程都适合慕课的形式, 比如有些文 科课程, 完全采用慕课的形式, 并不能取得理想的教学 效果。也不是所有的人都适合慕课学习, 只有那些有学 习动力、进取心强、自制力强的人, 通过慕课学习才会 取得令人满意的效果, 而这些人无论通过什么样的方式 学习, 都会获得成功。那些没有学习动力、自我管理能 力和学习能力比较差的人, 如果选择慕课学习, 无论课 
程质量多么高, 他们也很可能坚持不下去。这一点, 我 们从有些课程高达 $80 \% \sim 95 \%$ 的退出率就能看出 来。因此, 课程质量的优秀并不意味着培养质量的优秀

\section{5. 结语}

作为互联网技术与教育深度融合的产物, 慕课对高等 教育的积极作用不容忽视。它能有效促进教育公平, 显著 提高教育质量和效果, 迅速更新教育理念。因此, 我们应 该积极利用和发展慕课, 推动教学改革, 更好地满足社会 需求。但是, 我们也要看到慕课仅仅是一种教育方法和手 段, 而不是教育的目的。如果我们为慕课而慕课, 把所有 的课程都生硬的套入到慕课的形式中, 也不会取得我们想 要获得的效果。慕课作为重构学习方式的一种途径, 既不 是唯一的教育手段, 也不可能取代传统的高等教育。

\section{参考文献(References)}

[1] Zhiyuan Zhang, "The Moocs and Chinese higher education," Journal of Hebei Normal University, vol.16, no. 2, pp. 116-121, March 2014.

[2] Wanwei Wu, "Sober Reflactions about MOCC Mania," Fudan
Education Forum, vol.12, no. 11, pp. 10-17, March 2014..

[3] Mingwen Jiang,Xingzhou Li, "Meditations on the Enthusiasm for MOOCs," Journal of Hebei Normal University, vol.16, no. 2, pp. 110-115, March 2014.

[4] Qiong Wang, "MOOCs Change the Traditional Teaching," the Chinese journal of ICT in Education, no.19, pp. 26-28, October 2013.

[5] Lunqiang Ye, "The Research of the MOOCs Platform Based on Virtualization," Journal of Southwest University for Nationaities, vol.40, no.4, pp.553-558, Jul 2014.

[6] Andy Lane,Sally Caird and Martin Weller, "The Potential Social Economic and Environmental Benefits of MOOCs:Operational and Historical Comparisons with a Massive "Closed Online"Course , Distance Education in China, vol.16, no. 2, pp. 18-23,Feb 2015.

[7] Shirley A.Williams, Melissa M.Terras, Claire Warwick, "What do People Study When They Study Twitter? Classifying Twitter Related Academic Papers", Journal of Documentation, vol.69, no.3, pp. 384-410,June 2013. 